\title{
Anti-Inflammatory Effects of the Chinese Herbal Formula Sini Tang in Myocardial Infarction Rats
}

\author{
Jiangang Liu, ${ }^{1}$ Karoline Peter, ${ }^{2}$ Dazhuo Shi, ${ }^{1}$ Lei Zhang, ${ }^{1}$ Guoju Dong, ${ }^{1}$ Dawu Zhang, \\ Heimo Breiteneder, ${ }^{2}$ Rudolf Bauer, ${ }^{3}$ Johannes Jakowitsch, ${ }^{4}$ and Yan $\mathrm{Ma}^{2}$ \\ ${ }^{1}$ Center of Cardiology, Xiyuan Hospital, China Academy of Chinese Medical Sciences, No. 1 Xiyuan Caochang, \\ Haidian District, Beijing 100091, China \\ ${ }^{2}$ Molecular Research in Traditional Chinese Medicine Group, Department of Pathophysiology and Allergy Research, \\ Vienna General Hospital, Medical University of Vienna, Waehringer Guertel 18-20, 1090 Vienna, Austria \\ ${ }^{3}$ Department of Pharmacognosy, Institute of Pharmaceutical Sciences, University of Graz, Universitaetsplatz 4/I, 8010 Graz, Austria \\ ${ }^{4}$ Clinical Division of Cardiology, Department of Internal Medicine II, Vienna General Hospital, \\ Medical University of Vienna, Waehringer Guertel 18-20, 1090 Vienna, Austria
}

Correspondence should be addressed to Dazhuo Shi; shidazhuo@126.com and Yan Ma; yan.ma@meduniwien.ac.at

Received 3 November 2013; Revised 24 January 2014; Accepted 27 January 2014; Published 3 March 2014

Academic Editor: Joen-Rong Sheu

Copyright (C) 2014 Jiangang Liu et al. This is an open access article distributed under the Creative Commons Attribution License, which permits unrestricted use, distribution, and reproduction in any medium, provided the original work is properly cited.

\begin{abstract}
The aim of this study was to evaluate the anti-inflammatory profiling of the Chinese herbal formula Sini Tang (SNT) in myocardial infarction (MI) rats. SNT, a decoction consisting of four herbs: Aconitum carmichaelii, Cinnamomum cassia, Zingiber officinale, and Glycyrrhiza uralensis, was characterized as a remedy to treat syndromes corresponding to heart failure and MI in China. Potential biomarkers, which reflect the extent of myocardial necrosis and correlate with cardiac outcomes following MI, such as atrial natriuretic peptide (ANP), high sensitivity C-reactive protein (hs-CRP), and proinflammatory cytokines such as tumor necrosis factor- $\alpha$, interleukin- 6 , and interleukin- $\beta$ (TNF- $\alpha$, IL-6, and IL- $1 \beta$ ) were determined in plasma, serum, and in myocardial tissue of MI rats after treatment with SNT. Our data indicate that SNT decreased significantly the levels of hs-CRP, TNF- $\alpha$, IL-6, and IL-1 $\beta$ in MI rats. SNT decreased the expression of ANP levels in plasma and increased the vascular active marker nitric oxide, which limits vascular inflammation. In addition, SNT could decrease the expression of endothelin-1 levels in rat plasma post-MI. Our data suggest that the Chinese herbal formula SNT has the potential to improve cardiac function after MI. SNT may be a candidate for treating MI and its associated inflammatory responses.
\end{abstract}

\section{Introduction}

Heart failure (HF) is a critical disease. Currently 26 million people are suffering from HF worldwide, one quarter of them in Europe [1]. One of the major causes of HF is myocardial infarction (MI). Every sixth man and every seventh woman in Europe died from MI [2]. MI is associated with an inflammatory reaction, which is a prerequisite for healing and scar formation $[3,4]$. Inflammatory markers such as interleukin-6 (IL-6), interleukin-1 $\beta$ (IL-1 $\beta$ ), high sensitivity C-reactive protein (hs-CRP), and tumor necrosis factor- $\alpha$ (TNF- $\alpha$ ) reflect the extent of myocardial necrosis and correlate with cardiac outcomes following MI [5-7].
Traditional Chinese medicine (TCM) has been used in China for centuries for treatment of cardiac disease and is now attracting interest in Western countries as a source of alternative or complementary therapies due to its reputed effectiveness, low cost, and relative absence of side effects. Previous studies provided scientific evidence to support the use of Chinese herbal medicine for treating MI and HF [813]. A TCM Sini Tang decoction (SNT), which consists of four Chinese medical herbs, the root of Sichuan aconite (Aconitum carmichaelii Debeaux, Ranunculaceae), the bark of Chinese cinnamon (Cinnamomum cassia J. Presl., Lauraceae), the rhizome of ginger (Zingiber officinale Roscoe, Zingiberaceae), and the root of Chinese licorice (Glycyrrhiza uralensis Fisch. 
TABLE 1: Composition of the Chinese herbal formula SNT.

\begin{tabular}{lcccc}
\hline Pin Yin & Chinese & Common & Latin & Amount/weight ratio \\
\hline Zhi Fu Zi & 制附子 & Aconite & Aconitum carmichaelii & 6 \\
Rou Gui & 肉桂 & Cinnamon & Cinnamomum cassia & 1 \\
Gan Jiang & 干姜 & Ginger & Zingiber officinale & 3 \\
Jiu Gan Cao & 炎甘草 & Licorice & Glycyrrhiza uralensis & 8 \\
\hline
\end{tabular}

ex DC. Fabaceae) [14], was used in preliminary and previous studies in a MI rat model $[15,16]$ (Table 1$)$.

The crude aconite contains the highly toxic diesterditerpenoid alkaloids aconitine, hypaconitine, and mesaconitine. Our previous results indicated that SNT is suitable and safe for the rat model and has the potential to improve early ventricular remodeling and cardiac function after MI. SNT reduced collagen matrix accumulation in the serum and in the myocardial tissue, which is associated with a significant improvement in systolic function. Furthermore, SNT decreased the expression of Toll-like receptors (TLRs) levels in the myocardial tissue. TLRs belong to a group of type I transmembrane receptors with endogenous and exogenous ligand binding ability to stimulate innate and adaptive immune responses and induce immune and inflammatory cytokines IL-6, TNF-alpha, and other gene transcriptions and protein expressions [17-20].

In this study we aimed to confirm these preliminary observations by evaluating a number of potential biomarkers and proinflammatory cytokines as well as atrial natriuretic peptide (ANP), the potent vasoconstrictor endothelin-1 (ET1 ), and the vascular active marker nitric oxide (NO), which limits vascular inflammation and plays an important role in cardiac remodeling and wound repair after MI [21-24]. ANP conveys the cardiac protective properties of vasodilation, inhibition of cardiomyocyte hypertrophy, cardiac fibroblast proliferation, collagen synthesis, and enhanced lipolysis [25]. ANP and other natriuretic peptides are the gold standard biomarkers in determining the diagnosis and prognosis of HF following MI [26]. During acute myocardial infarction, ET1 enhances myocardial necrosis and arrhythmogenesis but seems to exert a favorable effect on subsequent infarct healing and early ventricular remodeling [27]. Thus ANP, ET-1, and $\mathrm{NO}$ were measured and evaluated in rat plasma and serum in this study.

Compared to our previous studies we optimized the dosage of administration by using a low as well as a high dose of SNT in this study. We also used fosinopril sodium which is indicated for the treatment of $\operatorname{HF}[28,29]$ and decreases the inflammatory response after MI [30] as a positive control.

\section{Materials and Methods}

2.1. Animals. All animal experiments were approved by the Administrative Committee of Experimental Animal Care and Use of China Academy of Chinese Medical Sciences (CACMS, Permit number CACMS/20100322) and conformed to the National Institute of Health Guide for the Care and Use of Laboratory Animals [31].
We used 90 (50\% male and 50\% female) Sprague-Dawley rats (180-200 g) provided by the Vital Laboratory Animal Technology Company (Beijing, China) for this study. Rats were acclimatized with a 12/12 hours light/dark cycle at a controlled room temperature of $23-25^{\circ} \mathrm{C}$ and a humidity of $50-70 \%$, and rats were allowed free access to food and water for seven days before use.

2.2. Drugs and Reagents Information. Chemical standards of aconitine, mesaconitine, and hypaconitine were purchased from PhytoLab GmbH, Germany. Fosinopril sodium (FS) (10 mg/tablet) was supplied by Sino-American Shanghai Squibb Pharmaceutical Co., Ltd. (China). Atrial natriuretic peptide (ANP) Kit, total nitric oxide (NO), and endothelin 1 (ET-1) were purchased from GBD Ltd., USA. Interleukin$1 \beta$ (IL-1 $\beta$ ), interleukin-6 (IL-6), high sensitivity C-reactive protein (hs-CRP), and tumor necrosis factor- $\alpha$ (TNF- $\alpha$ ) Kits were provided by R\&D systems (USA). Coomassie blue protein assay Kit was offered by Nanjing Science and Technology Co., Ltd. (China). The Two-step Immunohistochemical Detection Kit was produced by Zhongshan Golden Bridge Biotechnology Co., Ltd. (Beijing, China).

\subsection{Preparation of SNT Decoction. SNT $(0.5 \mathrm{~g} / \mathrm{g}$} extract/crude drug) including processed Glycyrrhiza uralensis, processed Aconitum carmichaelii, Zingiber officinale, and Cinnamomum cassia was prepared at the Pharmacy Department of Xiyuan Hospital, China Academy of Traditional Chinese Medicine (Beijing, China). Aconite was cut into small pieces before use. Herbs were soaked in sterilized drinking water $(500 \mathrm{~mL})$ for one hour in a clay pot at room temperature and cooked to boiling. The decoction was performed twice by cooking gently for $30 \mathrm{~min}$ each. The two obtained decocts were combined, filtered, and stored at $4^{\circ} \mathrm{C}$ before administration to rats [16].

2.4. Quality Control of SNT by HPLC. HPLC analysis of SNT decoctions was developed during this study using an agilent 1100 series LC system equipped with a Hypersil BDS RPC-18 column $(100 \times 3 \mathrm{~mm}$; particle size $3 \mathrm{~mm}$, Agilent, Germany) as described by Peter et al. [16]. A mixed standard solution of aconitine $(160 \mu \mathrm{g})$, mesaconitine $(150 \mu \mathrm{g})$, and hypaconitine $(230 \mu \mathrm{g})$ in $1 \mathrm{~mL}$ acetonitrile $/ \mathrm{H}_{2} \mathrm{O}(80: 20)$ was prepared. The mobile phase was a mixture of buffer A (an aqueous buffer, $\mathrm{pH} 3$, containing $15 \mathrm{mM}$ ortho-phosphoric acid and $1.5 \mathrm{mM}$ tetrabutylammonium hydroxide) and buffer $\mathrm{B}$ ( $0.01 \%$ formic acid in acetonitrile). Buffer $\mathrm{A}$ and buffer $\mathrm{B}$ were used for gradient elution (5-24.4\% of buffer B at 0-11 min, 24.4-26\% 
of buffer B at 11-17 min, 26-40\% of buffer B at 17-18 min, 40$100 \%$ of buffer B at $18-18.1 \mathrm{~min}$, and $100 \%$ of buffer B at $18.1-$ $23 \mathrm{~min}$ ). The injection volume was $5 \mu \mathrm{L}$ and the flow rate was kept at $0.5 \mathrm{~mL} / \mathrm{min}$ at $25^{\circ} \mathrm{C}$. The detection wavelength was set at $203 \mathrm{~nm}$. The content of aconitine, hypaconitine, and mesaconitine samples was calculated according to Csupor et al. [32].

2.5. MI Model of Rats. Acute myocardial infarction (AMI) was induced in both male and female rats by left anterior descending artery (LAD) ligation. The surgical procedures were performed using the well-established technique [33, 34]. These experiments were carried out strictly in accordance with the recommendations in the national legislation of China and performed at the Center of Animals Laboratory of the Beijing Xiyuan Hospital, China Academy of Chinese Medical Sciences. All surgeries were performed under diethyl ether anesthesia and all efforts were made to minimize suffering. Rats were anesthetized with diethyl ether and placed in a supine position on a table for the operations. The left anterior descending artery (LAD) was occluded as described by Dietl et al. [15]. To prevent infection rats were given penicillin (40.000 units) after the operation for 3 days. Sixty surviving infarct rats were randomly divided into five groups (Table 2). The oral administration of the drugs began two days after AMI-induction. SNT and FS, an angiotensin converting enzyme (ACE) inhibitor as a positive control, were diluted with distilled drinking water and administered orally in a volume of $10 \mathrm{~mL} / \mathrm{kg}$ body weight once every morning for 4 weeks.

2.6. Echocardiography Assessment. Echocardiography was performed 30 days after surgery according to the method described by Yin et al. [35]. Ten rats from each group were anesthetized by intraperitoneal injection of ethyl carbamate $(6 \mathrm{~mL} / \mathrm{kg})$. After cleaning the rat chest the cardiac short axis (papillary level), left ventricle end-diastolic dimension (LVDd), and left ventricle end-systolic dimension (LVDs) were measured using an ATL HDI-5000 Diagnostic Ultrasound System (Philips Ultrasound Inc., China). The ejection fraction (EF) was calculated from the left ventricle enddiastolic volume (LVEDV) and the left ventricle end-systolic volume (LVESV) as EF\% = [(LVEDV - LVESV)/LVEDV $]$ $\times 100$. The data calculations were performed using a singleblind method $[36,37]$.

2.7. Measurement of Myocardial Infarct Size (IS). The pathological slice was photographed in microdistance using a Canon IXUS 90IS digital camera. The microscopic color image processing system (DpxView Pro, Korea) was used to calculate the left ventricular IS (\%, myocardial infarction area/left ventricular area $\times 100$ ) by an investigator who was blinded to the identity of the pathological slice as described by Takagawa et al. [38].

2.8. Collection of Blood and Tissue Samples. After four weeks, the anesthetized rats were sacrificed. Blood samples were taken from the left ventricle (LV) cavity and centrifuged at
TABLE 2: The experimental rats groups. Drugs and decocts diluted with distilled drinking water were administered orally once a day for 30 days starting two days after induction of AMI.

\begin{tabular}{lccccc}
\hline Group & Sham & Model & FS & SNT-LD & SNT-HD \\
$N$ & 10 & 10 & 10 & 10 & 10 \\
Operation & Sham & AMI & AMI & AMI & AMI \\
Oral administration DW & DW & $0.9 \mathrm{mg} / \mathrm{kg}$ & $4.5 \mathrm{~g} / \mathrm{kg}$ & $13.5 \mathrm{~g} / \mathrm{kg}$ \\
\hline
\end{tabular}

Sham: sham operated.

AMI: induced acute myocardial infarction.

DW: drinking water.

FS: fosinopril sodium $(0.9 \mathrm{mg} / \mathrm{kg})$.

SNT-LD: low dose of SNT $(4.5 \mathrm{~g} / \mathrm{kg})$.

SNT-HD: high dose of SNT $(13.5 \mathrm{~g} / \mathrm{kg})$.

$3000 \mathrm{rpm}$ for $15 \mathrm{~min}$. Plasma and sera were obtained and conserved at $-80^{\circ} \mathrm{C}$ for further analysis. The heart tissue were collected, weighed, and randomly assigned. One heart of each group was stored at $-80^{\circ} \mathrm{C}$ for ELISA.

2.9. ELISA Assay of Serum, Plasma and Heart Tissue. Five of the twelve frozen heart tissue samples of each group were randomly picked. The heart sections were weighed and $300 \mathrm{mg}$ of each sample was cut into small pieces and $1 \mathrm{~mL}$ of saline solution was added. After homogenization on ice, samples were centrifuged and the supernatants were stored at $-80^{\circ} \mathrm{C}$ for analysis. ELISA tests were performed strictly according to the instructions. The protein concentration of each tissue sample was measured with the BCA (bicinchoninic acid) Protein Assay Kit (Thermo Fisher Scientific Inc., USA).

The following biomarkers, known to be involved in the process of cardiac remodeling, were determined by ELISA $[39,40]$. Functional index ANP, proinflammatory cytokines IL-6, IL-1 $\beta$, and TNF- $\alpha$, inflammatory biomarker hs-CRP, and vascular active markers ET-1 and NO were measured in plasma, serum, and myocardial tissue samples according to the manufacturer's instructions.

2.10. Statistical Analysis. Data were tabulated and presented as mean \pm standard deviation, and the significance of changes was assessed with one-way repeated measures analysis of variance (ANOVA). All results were tested on normal distribution by aid of One-Sample Kolmogorov-Smirnov Test. Bonferroni's Holm test was followed for multiple comparisons. One-way ANOVA Tukey HSD test was used for pairwise multiple comparisons. A value of $P<0.05$ was considered statistically significant. Data were analyzed using the Statistical Package for the Social Sciences (SPSS Inc., Chicago, USA).

\section{Results}

3.1. Quality Control of SNT by HPLC. The retention times of HPLC measurement of SNT decoction and the standards mixture of aconitine, mesaconitine, and hypaconitine were under the same chromatographic conditions (Figure 1). However, no aconitine, mesaconitine, and hypaconitine were 


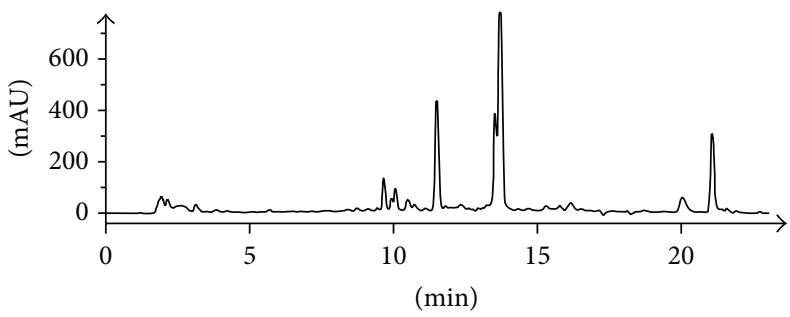

(a)

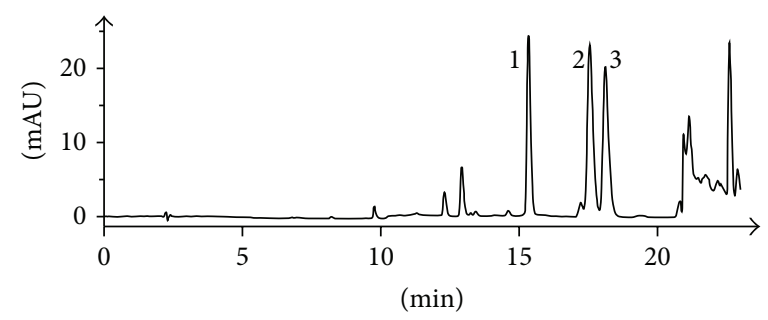

(b)

FIGURE 1: Quality control and toxicity evaluation of SNT by HPLC. (a) HPLC measurement of SNT. (b) The standard solution of diesterditerpenoid alkaloids: (1) mesaconitine, (2) hypaconitine, and (3) aconitine. mAU: milli absorption units.

TABLE 3: Echocardiographic parameters overview of ventricular remodeling effects.

\begin{tabular}{|c|c|c|c|c|c|c|}
\hline & Sham & Model & FS & SNT-LD & SNT-HD & Remodeling effects (versus model) \\
\hline LVDs (mm) & $0.91 \pm 0.20$ & $6.44 \pm 1.59^{* *}$ & $3.81 \pm 1.21^{* * \mathbf{\Delta} \boldsymbol{\Delta}}$ & $4.95 \pm 1.95^{* *}$ & $3.74 \pm 1.47^{* * \mathbf{\Delta}}$ & $\downarrow$ \\
\hline LVDd $(\mathrm{mm})$ & $3.29 \pm 0.81$ & $6.24 \pm 0.72^{* *}$ & $4.45 \pm 1.28$ & $5.37 \pm 1.78$ & $4.87 \pm 1.47$ & $\downarrow$ \\
\hline $\mathrm{EF}(\%)$ & $93.32 \pm 2.94$ & $55.48 \pm 12.89^{* *}$ & $78.03 \pm 10.70^{* \mathbf{\Lambda \Lambda}}$ & $69.69 \pm 13.91^{* * \boldsymbol{\Lambda}}$ & $77.83 \pm 12.32^{* \boldsymbol{\Lambda}}$ & $\uparrow$ \\
\hline IS $\left(\mathrm{mm}^{2}\right)$ & & $38.04 \pm 8.35$ & $23.91 \pm 7.99^{\mathbf{\Lambda}}$ & $31.25 \pm 10.68$ & $27.81 \pm 4.91^{\mathbf{\Lambda}}$ & $\downarrow$ \\
\hline
\end{tabular}

${ }^{*} P<0.05,{ }^{* *} P<0.01$ versus sham group; ${ }^{\mathbf{\Lambda}} P<0.05,{ }^{\mathbf{\Lambda}} P<0.01$ versus model group.

detected in the SNT decoction. SNT is suitable and safe for the rat model used in this study.

3.2. Effects of SNT on Echocardiography. Four weeks after MI, ultrasound echocardiography showed a significant increase of the left ventricular dimension at end diastole (LVDd) and the left ventricular dimension at end systole (LVDs) in the model group $(6.24 \pm 0.72 \mathrm{~mm}$ versus $3.29 \pm 0.81$ and $6.44 \pm$ $1.59 \mathrm{~mm}$ versus $0.91 \pm 0.20, P<0.05)$ compared to the sham group. The FS and SNT treatment groups exhibited significantly decreased LVDs versus the sham group (FS: $3.81 \pm 1.21 \mathrm{~mm}$, SNT-LD: $4.95 \pm 1.95 \mathrm{~mm}$ and SNT-HD: $3.74 \pm 1.47 \mathrm{~mm}, P<0.01)$. The FS treatment group exhibited significantly decreased LVDd $(4.45 \pm 1.28 \mathrm{~mm}$ versus $3.29 \pm$ $0.81 \mathrm{~mm}, P<0.01)$. The SNT treatment groups also showed decreased LVDd versus the sham group (SNT-LD: $5.37 \pm$ $1.78 \mathrm{~mm}$ and SNT-HD: $4.87 \pm 1.47 \mathrm{~mm}, P>0.05$ ), but not significantly. The left ventricular ejection fraction (EF) was significantly lower in the model group compared to the sham group $(55.48 \pm 12.89 \%$ versus $93.32 \pm 2.94 \%, P<0.01)$. The FS and SNT treatment groups showed an improved left ventricular function of the EF compared to the sham (FS: $78.03 \pm 10.70 \%$, SNT-LD: $69.69 \pm 13.9 \%, P<0.05$ and SNT-HD: $77.83 \pm 12.32 \%, P<0.01)$ and model groups (FS and SNT-HD: $P<0.01$, SNT-LD: $P<0.05$ ). SNT treatment improved the cardiac function by increasing the EF by $23.63 \%$ (difference between sham group: $93.32 \%$ and SNTLD: 69.69\%), (Table 3 and Figure 2).

3.3. Effects of SNT on Infarct Size. The infarct size (IS) obtained using the midline length measurement is shown in Table 3. The IS values from the FS, SNT-LD and SNT-HD groups $\left(23.91 \pm 7.99 \mathrm{~mm}^{2}, P<0.01,31.25 \pm 10.68 \mathrm{~mm}^{2}\right.$ and $\left.27.81 \pm 10.33 \mathrm{~mm}^{2}, P<0.05\right)$ were significantly smaller than from the model group $\left(38.04 \pm 8.35 \mathrm{~mm}^{2}\right)$.
3.4. Effects of SNT on ANP. In comparison with the sham group, the plasma ANP levels of rats in three treatment groups were decreased after four weeks (FS: $222.26 \pm$ $80.25 \mathrm{ng} / \mathrm{L}$ and SNT-LD and SNT-HD: $224.82 \pm 80.19 \mathrm{ng} / \mathrm{L}$ and $189.05 \pm 49.96 \mathrm{ng} / \mathrm{L}$ versus the sham group: $250.00 \pm$ $21.32 \mathrm{ng} / \mathrm{L})$. In comparison with the model group, the SNTHD group showed more reduction of the ANP content (SNTHD versus model group: $367.34 \pm 43.20, P<0.01)$. The data are shown in Table 4 and Figure 3.

3.5. Effects of SNT on ET-1 and NO. Four weeks after ischemia the ET-1 levels of the treatment groups were decreased compared to model group (FS: $166.15 \pm 9.01 \mathrm{ng} / \mathrm{L}$, SNTLD: $166.74 \pm 7.70 \mathrm{ng} / \mathrm{L}$, and SNT-HD: $158.49 \pm 9.97 \mathrm{ng} / \mathrm{L}$ versus model group: $171.09 \pm 13.17 \mathrm{ng} / \mathrm{L})$. In comparison to the model group the NO levels of all treatment groups were increased (FS: $53.78 \pm 6.24 \mu \mathrm{mol} / \mathrm{L}$, SNT-LD: $53.06 \pm$ $11.54 \mu \mathrm{mol} / \mathrm{L}$, and SNT-HD: $64.85 \pm 8.74 \mu \mathrm{mol} / \mathrm{L}$ versus model group: $48.18 \pm 10.14 \mu \mathrm{mol} / \mathrm{L})$. The SNT-HD group showed a significant difference $(P<0.05)$ in the NO level compared to model group. The data are shown in Table 4 and Figure 3.

3.6. Effects of SNT on Serum and Myocardial Tissue Levels of Inflammatory Factors. The levels of inflammatory biomarker and cytokines hs-CRP, IL- 6 , IL- $1 \beta$, and TNF- $\alpha$ in rat serum and myocardial tissue were decreased in the treatment groups (Table 5 and Figure 4). The treatment groups showed a significant difference in the level of hs-CRP in comparison to the model group (FS: $5.02 \pm 0.71 \mathrm{mg} / \mathrm{L}$, SNT-LD: $3.94 \pm$ $0.61 \mathrm{mg} / \mathrm{L}$, and SNT-HD: $3.97 \pm 0.77 \mathrm{mg} / \mathrm{L}$ versus model group: $6.71 \pm 0.70 \mathrm{mg} / \mathrm{L}, P<0.01)$. The treatment groups showed a decrease in the level of IL- 6 compared to model group (FS: $210.60 \pm 38.83 \mathrm{ng} / \mathrm{L}$, SNT-LD: $196.81 \pm 22.68 \mathrm{ng} / \mathrm{L}$, and SNT-HD: $202.55 \pm 37.37 \mathrm{ng} / \mathrm{L}$ versus model group: 


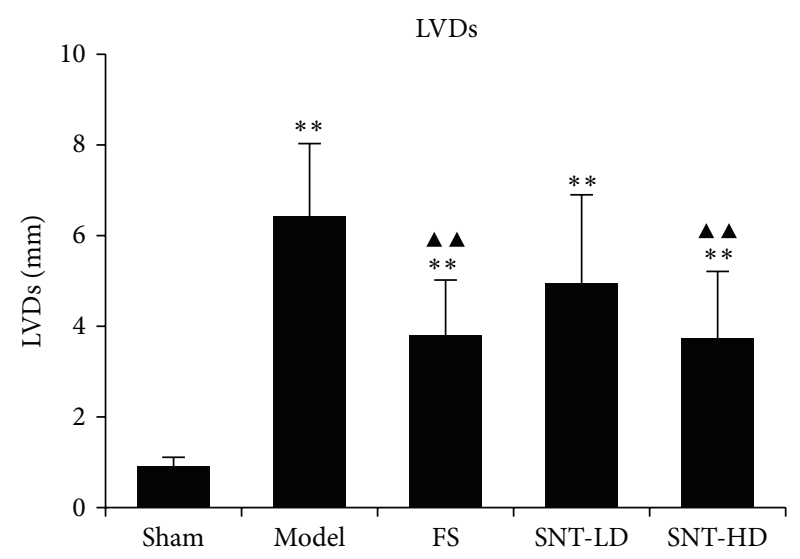

(a)

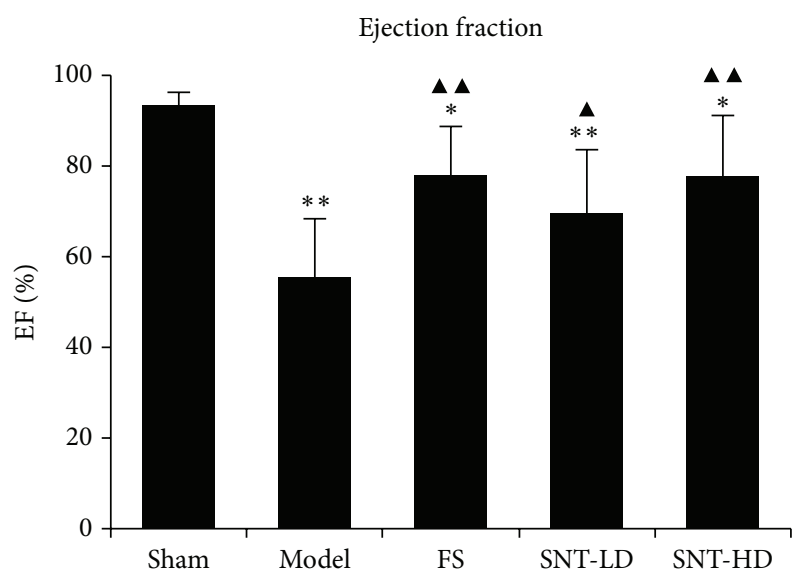

(c)

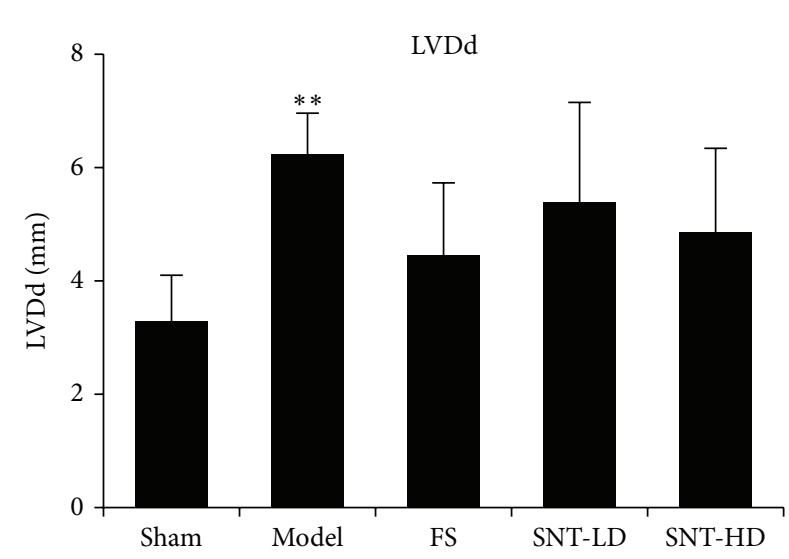

(b)

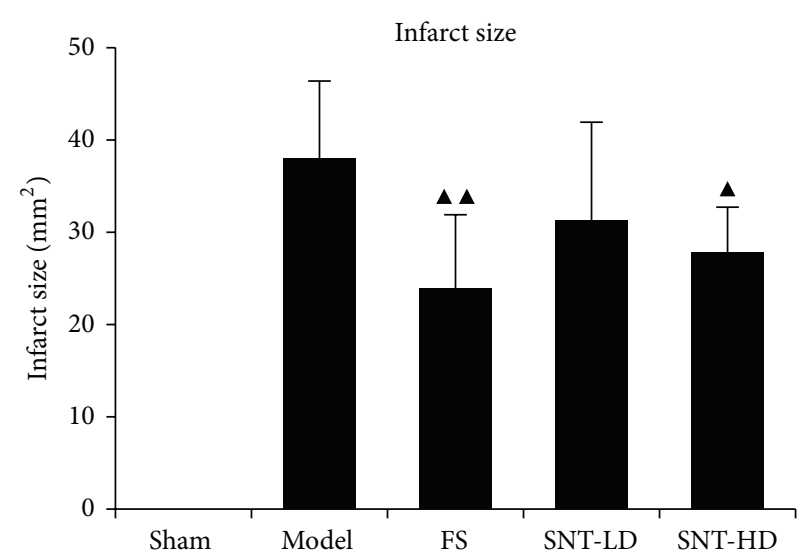

(d)

FIGURE 2: Echocardiographic parameters. (a) Echocardiographic measurements of left ventricular dimension at end systole (LVDs), (b) left ventricular dimension at end diastole (LVDd), (c) left ventricular ejection fraction (EF), and (d) infarct size results.

TABLE 4: Overview of vascular functional index marker expression levels in serum or in plasma $(\bar{x} \pm s)$.

\begin{tabular}{lcccccc}
\hline & Sham & Model & FS & SNT-LD & SNT-HD & Expression levels (versus model) \\
\hline ET $(\mathrm{ng} / \mathrm{L})$ & $161.40 \pm 13.95$ & $171.09 \pm 13.17$ & $166.15 \pm 9.01$ & $166.74 \pm 7.70$ & $158.49 \pm 9.97$ & $\downarrow$ \\
NO $(\mu \mathrm{mol} / \mathrm{L})$ & $54.04 \pm 11.88$ & $48.18 \pm 10.14$ & $53.78 \pm 6.24$ & $53.06 \pm 11.54$ & $64.85 \pm 8.74^{\mathbf{\Delta}}$ & $\uparrow$ \\
NO/ET & 3.35 & 2.83 & 3.24 & 3.18 & $4.09^{* * \mathbf{\Delta}}$ & $\uparrow$ \\
ANP $(\mathrm{ng} / \mathrm{L})$ & $250.00 \pm 21.32$ & $367.34 \pm 43.20$ & $222.26 \pm 80.25$ & $224.82 \pm 80.19$ & $189.05 \pm 49.96^{\mathbf{\Delta}}$ & $\downarrow$ \\
\hline
\end{tabular}

ET and ANP were measured in plasma. NO was measured in serum.

${ }^{* *} P<0.01$ versus sham group, ${ }^{\mathbf{\Lambda}} P<0.05,{ }^{\mathbf{\Lambda}} P<0.01$ versus model group.

$240.65 \pm 27.80 \mathrm{ng} / \mathrm{L})$. The levels of TNF- $\alpha$ were decreased significantly in FS and SNT-HD groups compared to the model group (FS: $22.17 \pm 8.66 \mathrm{ng} / \mathrm{L}, P<0.05$; SNT-LD: $25.61 \pm 7.57 \mathrm{ng} / \mathrm{L}$ and SNT-HD: $23.94 \pm 4.27 \mathrm{ng} / \mathrm{L}, P<$ 0.05 versus model group: $33.23 \pm 5.78 \mathrm{ng} / \mathrm{L}$ ). The levels of IL-1 $\beta$ were decreased significantly in serum (FS: $151.17 \pm$ $16.62 \mathrm{ng} / \mathrm{L}, P<0.01 ;$ SNT-LD: $170.91 \pm 15.09 \mathrm{ng} / \mathrm{L}$ and SNT-HD: $170.8 \pm 23.30 \mathrm{ng} / \mathrm{L}, P<0.05$ versus model group: $199.86 \pm 25.44 \mathrm{ng} / \mathrm{L}$ ) as well as in myocardial tissue (FS: $32.85 \pm 3.64 \mathrm{ng} / \mathrm{g}, P<0.01 ;$ SNT-LD: $37.32 \pm 4.89 \mathrm{ng} / \mathrm{g}$ and SNT-HD ng/g, $P<0.05$ versus model group: $41.56 \pm$ $6.08 \mathrm{ng} / \mathrm{g})$.

\section{Discussion}

In China, Chinese herbal medicine is widely used as an adjunct to biomedicine in treating MI [41]. Our previous studies indicated that SNT is suitable and safe for the animal model study and has the potential to improve early ventricular remodeling and cardiac function after MI $[15,16]$. Pathological H\&E staining showed that the IS values from the FS and SNT groups $\left(23.91 \pm 7.99 \mathrm{~mm}^{2}, 31.25 \pm 10.68 \mathrm{~mm}^{2}\right.$ and $27.81 \pm 10.33 \mathrm{~mm}^{2}$ ) were smaller than from the model group $\left(38.04 \pm 8.35 \mathrm{~mm}^{2}\right)$. FS and SNT could decrease LVDs significantly in the FS and SNT-HD groups (FS: $3.81 \pm$ 


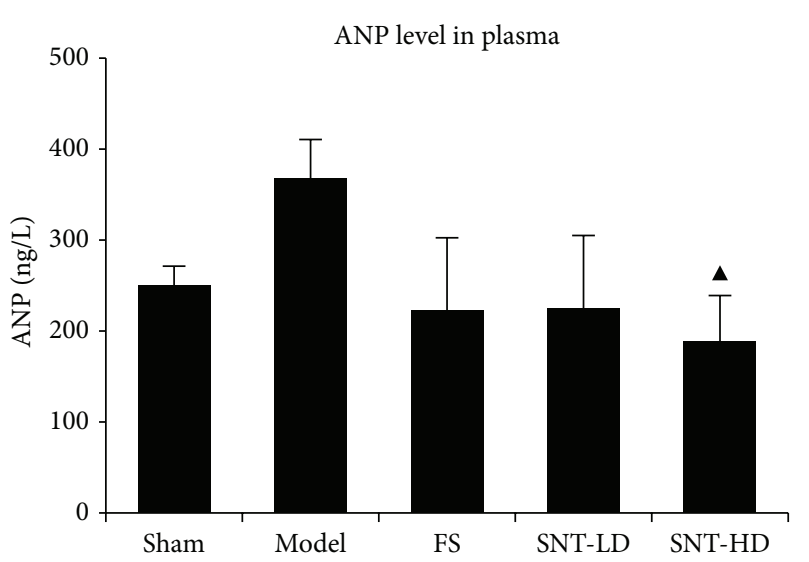

(a)

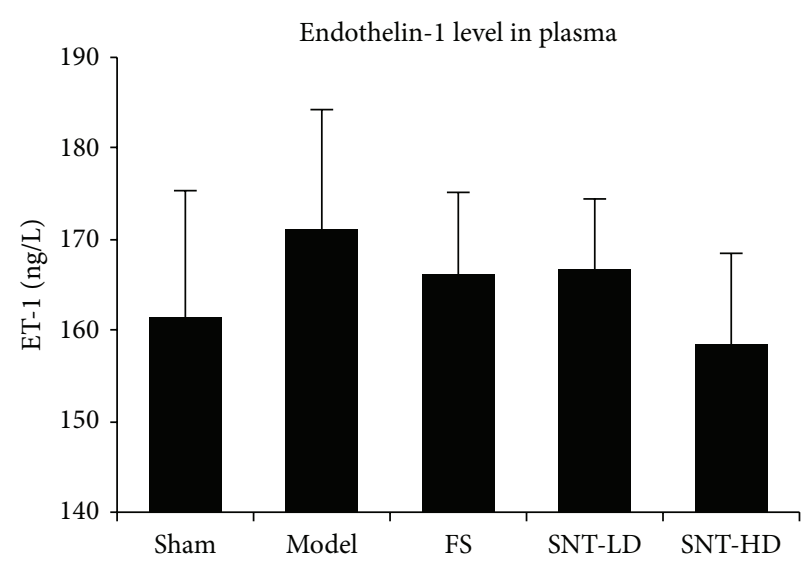

(b)

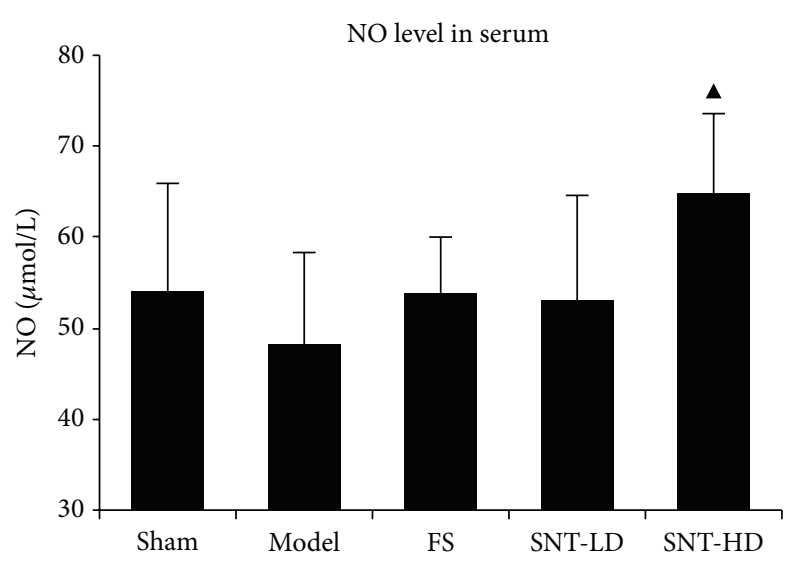

(c)

FIGURE 3: Effects of SNT on ANP, ET-1 levels in plasma, and NO levels in serum. ANP (atrial natriuretic peptide) levels (a) and ET-1 (endothelin-1) levels (b) in plasma. NO (nitric oxide) levels in serum (c). ANP and NO levels of the SNT-HD group were significantly more different than those of the model group $(P<0.05)$.

TABLE 5: Overview of inflammatory factors and cytokines levels in serum and in myocardial tissue.

\begin{tabular}{|c|c|c|c|c|c|c|}
\hline & Sham & Model & FS & SNT-LD & SNT-HD & Expression levels (versus model) \\
\hline \multicolumn{7}{|l|}{ In serum } \\
\hline hs-CRP (mg/L) & $4.53 \pm 0.66$ & $6.71 \pm 0.70^{* *}$ & $5.02 \pm 0.71^{\boldsymbol{\Lambda \Delta}}$ & $3.94 \pm 0.61^{\mathbf{\Lambda}}$ & $3.97 \pm 0.77^{\mathbf{\Lambda}}$ & $\downarrow$ \\
\hline IL-6 (ng/L) & $204.17 \pm 39.83$ & $240.65 \pm 27.80$ & $210.60 \pm 38.83$ & $196.81 \pm 22.68$ & $202.55 \pm 37.37$ & $\downarrow$ \\
\hline TNF- $\alpha(n g / L)$ & $23.38 \pm 7.10$ & $33.23 \pm 5.78^{* *}$ & $22.17 \pm 8.66^{\mathbf{\Lambda}}$ & $25.61 \pm 7.57$ & $23.94 \pm 4.27^{\boldsymbol{\Perp}}$ & $\downarrow$ \\
\hline IL-1 $\beta$ (ng/L) & $157.15 \pm 17.34$ & $199.86 \pm 25.44^{* *}$ & $151.17 \pm 16.62^{\mathbf{\Lambda}}$ & $170.91 \pm 15.09^{\mathbf{\Delta}}$ & $170.8 \pm 23.30^{\mathbf{\triangle}}$ & $\downarrow$ \\
\hline \multicolumn{7}{|l|}{ In myocardial tissue } \\
\hline IL-1 $\beta$ (ng/g) & $29.73 \pm 1.53$ & $41.56 \pm 6.08^{* *}$ & $32.85 \pm 3.64^{\mathbf{\Lambda}}$ & $37.32 \pm 4.89$ & $30.37 \pm 1.91^{\mathbf{\Lambda \Delta}}$ & $\downarrow$ \\
\hline
\end{tabular}

${ }^{* *} P<0.01$ versus sham group; ${ }^{\mathbf{\Delta}} P<0.05,{ }^{\mathbf{\Delta}} P<0.01$ versus model group.

$1.21 \mathrm{~mm}, P<0.01$; SNT-LD: $4.95 \pm 1.95 \mathrm{~mm}$ and SNT-HD: $3.74 \pm 1.47 \mathrm{~mm}, P<0.01$ versus the model group). FS and SNT could also decrease LVDd significantly only in the FS group (FS: $6.24 \pm 0.72 \mathrm{~mm}, P<0.05$, SNT-LD: $5.37 \pm 1.78 \mathrm{~mm}$, and SNT-HD: $4.87 \pm 1.47 \mathrm{~mm}$ versus the sham group). Echocardiography the key diagnostic tool and was performed to assess LV function and volumes, valvular function, extent of myocardial damage, and to detect complications [42]. The results of our echocardiographic evaluation indicated that the rats in the SNT treated groups had an improved left ventricular function. The left ventricular ejection fraction (EF\%) was significantly increased in all treatment groups compared with the model group $(P<0.05$ and $P<0.01)$. Quality control of SNT by HPLC showed that no toxic diesterditerpenoid alkaloids of aconite were detected in the SNT decoction. The present study suggests that the Chinese herbal medicine SNT might play an important role in the treatment of $\mathrm{MI}$ and its associated inflammatory reactions. 


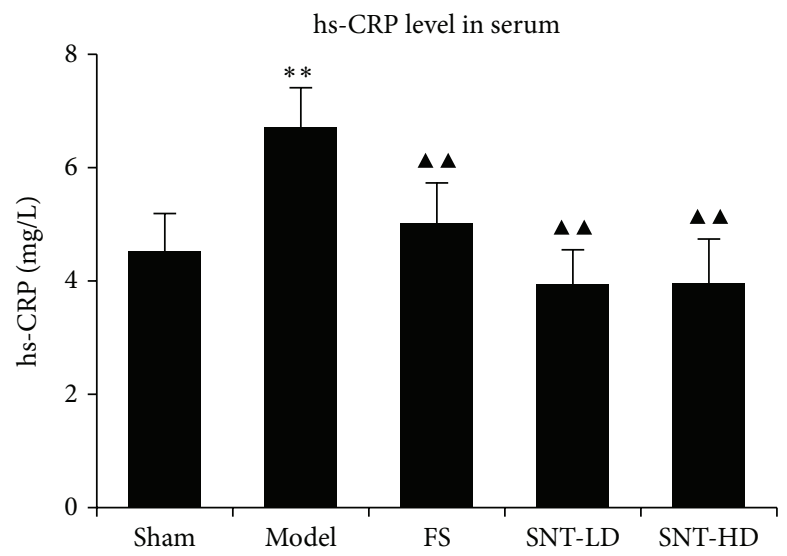

(a)

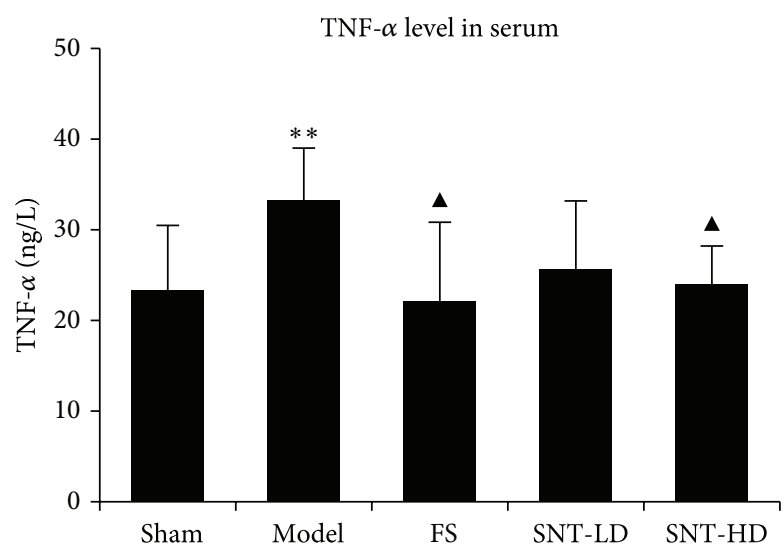

(c)

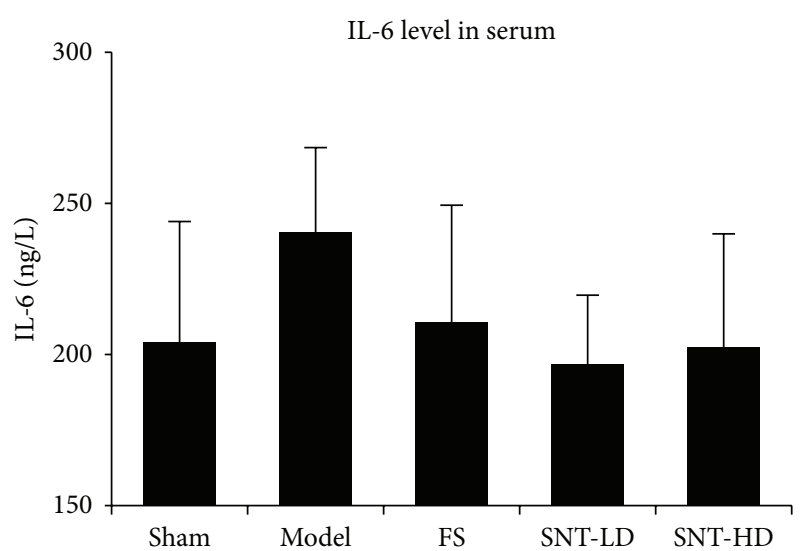

(b)

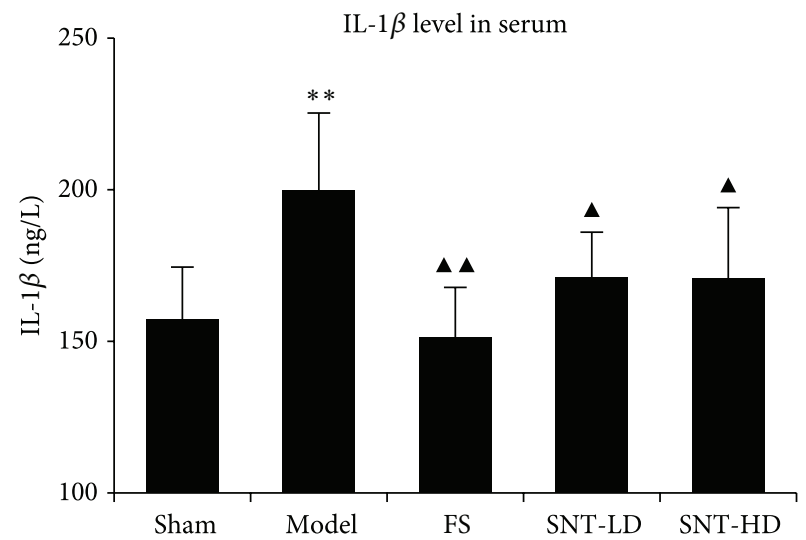

(d)

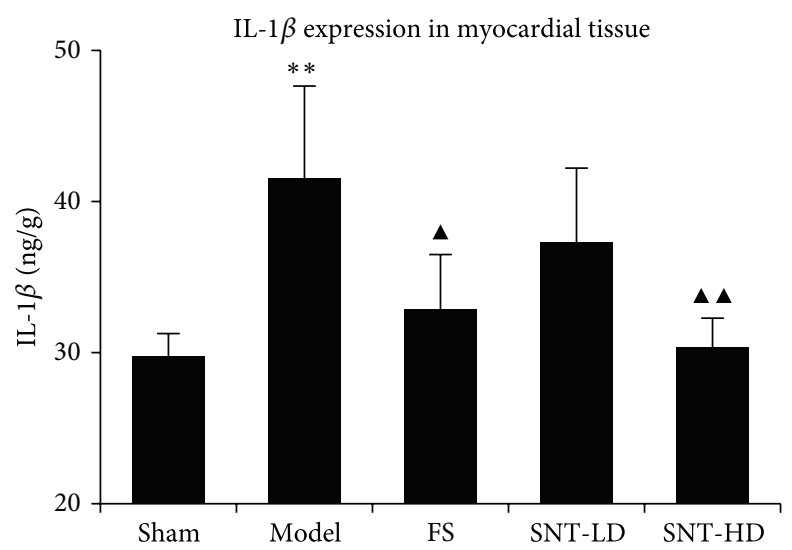

(e)

FIGURE 4: Effects of SNT on the levels of inflammatory factors in serum and myocardial tissue. The hs-CRP levels (a) of the FS and the SNT treatment groups showed significant decreases in comparison to the model group $(P<0.01)$. The IL-6 levels in serum (b) were reduced in the FS and SNT treatment groups. The TNF- $\alpha$ levels (c) of the treatment groups were reduced. FS and the SNT-HD groups showed significant decreases in comparison to the model group $(P<0.05)$. The IL-1 $\beta$ levels in serum $(\mathrm{d})$ were reduced in the FS and SNT groups $(P<0.01$ and $P<0.05$ versus model group, resp.). The IL- $1 \beta$ levels in myocardial tissue (e) were reduced in the FS and SNT groups and significantly in the FS and SNT-HD groups $(P<0.05$ and $P<0.01$, resp. $)$ compared to model group.

Endothelin-1 (ET-1), a potent vasoconstrictor, is synthesized in the vasculature and myocardium by various cell types and is associated with the development of cardiac dysfunction. Nitric oxide (NO) plays an important role in the homeostasis of the cardiovascular system by regulating vascular smooth muscle cell contractility and myocardial oxygen consumption [21]. NO acts as a key contributor to vascular health due to its effects of limiting vascular inflammation, platelet aggregation, monocyte adhesion to endothelial cells, and abnormal smooth muscle cell proliferation. Endothelial 
dysfunction is connected to a decreased bioavailability of vasodilators, especially NO [22]. The levels of ET-1 in the plasma were decreased in all treatment groups but did not show significant differences among the groups in our experiments. The SNT-HD treatment group showed more decrease than other treatment groups. Yang et al. reported the regulating effect of SNT on blood pressure because it adjusts the expression levels of endothelin receptor-A and endothelial NO synthesis in the heart and the vasoactive marker levels (ET and NO) in the blood [43]. The NO levels of all treatment groups were increased. In comparison to the model group the SNT-HD group showed a significant difference $(P<0.05)$ in the NO level. NO was affected by the treatment with SNT at high doses.

Atrial natriuretic peptide (ANP) acts as a vasodilator which is released in response to increasing atrial filling pressures [23]. The most important factor governing ANP secretion is mechanical stretching of the atria, which occurs when extracellular fluid volume or blood volume is elevated. The release of ANP in disease states such as MI and HF appears to be related to both mechanical and cellular events [24]. The levels of ANP in the plasma of all treatment groups were lower than in the model group, but only the high dose group showed a significant difference $(P<0.05)$. ANP was also affected by the treatment with SNT at high doses. The examination of a larger number of subjects may be necessary to discover significant differences between the experimental groups.

Biochemical markers like collagen metabolites, proinflammatory cytokines, and matrix metalloproteinases are getting increasingly important in ventricular remodeling research and clinic cardiology. An ideal biochemical marker of clinical cardiology should be a prognostic indicator, should assist in the early diagnosis, reliably reflect the therapeutic response, and help in grading the risk associated with each stage of MI $[38,39]$. CRP is an inflammatory biomarker which reflects the extent of myocardial necrosis and correlates with cardiac outcomes following AMI [6]. The inflammatory response and cytokines such as TNF- $\alpha$, IL-1 $\beta$, or IL-6 are increased soon after myocardial ischemic injury and can acutely regulate myocyte survival or apoptosis and trigger additional cellular inflammatory responses [7]. TNF- $\alpha$, IL-1 $\beta$, and IL- 6 are not constitutively expressed in the normal heart [44]. There are robust upregulations of intramyocardial cytokines including TNF- $\alpha$, IL- $1 \beta$, and IL6 mRNA expression in the infarct area and the noninfarcted myocardium after MI. In this study we could show that the levels of cytokines IL- 6 , IL- $1 \beta$, and TNF- $\alpha$ and hs-CRP in rat serum and myocardial tissue to be decreased in the FS and the SNT treatment groups with a significant difference in the levels of IL- $1 \beta$, TNF- $\alpha$, and hs-CRP. SNT might have potential anti-inflammatory effects. This was described in the "Science of Prescriptions," a newly compiled practical English-Chinese library of traditional Chinese medicine [45] and is in agreement with various studies [46-50], which reported the pharmacological properties of ginger as an antiinflammatory agent, the therapeutic function of cinnamon used for inflammatory diseases, fever, inflammation, chronic bronchitis, and for the improvement of blood circulation and the antigenotoxic and anti-inflammatory activities of licorice. To fully determine the anti-inflammatory effects of SNT thorough investigations should be performed including an evaluation of the number of infiltrating inflammatory cells and MI associated inflammatory cytokine levels in the future.

\section{Conclusions}

We evaluated the anti-inflammatory profiles of the Chinese herbal formula SNT, an ancient traditional medicinal formula using a rat model. Our data indicate that SNT could reverse ventricular remodeling and improve heart function. SNT has the potential to decrease the levels of hs-CRP and cytokines TNF- $\alpha$, IL- 6 , and IL- $1 \beta$ after MI.

SNT decreased the expression of ET-1 levels in the plasma and increased the vascular active marker nitric oxide. In addition, the SNT high-dose treatment group decreased the expression levels of ANP in plasma significantly. These new findings will help us to develop more successful therapies including SNT for treating MI and its associated inflammatory responses.

\section{Conflict of Interests}

The authors declare that there is no conflict of interests regarding the publication of this paper.

\section{Authors' Contribution}

Jiangang Liu and Karoline Peter contributed equally to the work.

\section{Acknowledgments}

This work was supported by the Austrian Federal Ministry of Science and Research and the Austrian Federal Ministry of Health (GZBMWF-402.000/3-11/6b/2008 to Yan Ma) and China International Scientific Cooperation and Exchange of Special Items (S2010BR0446 to Dazhuo Shi).

\section{References}

[1] J. López-Sendón, "The heart failure epidemic," Medicographia, vol. 33, pp. 363-369, 2011.

[2] P. G. Steg, S. K. James, D. Atar, L. P. Badano, and C. BlomstromLundqvist, "ESC guidelines for the management of acute myocardial infarction in patients presenting with ST-segment elevation," European Heart Journal, vol. 33, pp. 2569-2619, 2012.

[3] N. G. Frangogiannisa, C. W. Smithb, and L. M. Entmana, “The inflammatory response in myocardial infarction," Cardiovascular Research, vol. 53, pp. 31-47, 2002.

[4] J. L. Mehta and D. Y. Li, "Inflammation in ischemic heart disease: response to tissue injury or a pathogenetic villain?" Cardiovascular Research, vol. 43, no. 2, pp. 291-299, 1999.

[5] I. Morishima, T. Sone, H. Tsuboi et al., "Plasma C-reactive protein predicts left ventricular remodeling and function after a first acute anterior wall myocardial infarction treated with coronary angioplasty: comparison with brain natriuretic peptide," Clinical Cardiology, vol. 25, no. 3, pp. 112-116, 2002. 
[6] G. Berton, R. Cordiano, R. Palmieri, S. Pianca, V. Pagliara, and P. Palatini, "C-reactive protein in acute myocardial infarction: association with heart failure," American Heart Journal, vol. 145, no. 6, pp. 1094-1101, 2003.

[7] M. Nian, P. Lee, N. Khaper, and P. Liu, "Inflammatory cytokines and postmyocardial infarction remodeling," Circulation Research, vol. 94, no. 12, pp. 1543-1553, 2004.

[8] J. Tian, "Observation of treatment on 105 acute myocardial infarction patients using Si Ni Tang," Tian Jin Medical Reports, vol. 11, pp. 16-20, 1972.

[9] G. Li, W. Qi, and K. Xiong, "Clinical observation on 51 patients of acute myocardial infarction treated with thrombolytic therapy combined with Chinese herbal medicine," Chinese Journal of Integrated Traditional and Western Medicine, vol. 19, no. 8, pp. 461-462, 1999.

[10] Z.-T. Wang, S.-R. Wang, and M.-J. Zhao, "Comparative study on effect of recipe for activating blood circulation and replenishing Qi on left ventricular remodeling in rats with left heart failure after myocardial infarction," Chinese Journal of Integrated Traditional and Western Medicine, vol. 22, no. 5, pp. 376-378, 2002.

[11] Z. He, Y. Wu, M.-X. Jiang, R.-Q. Cheng, and R. Shen, "Observation by color doppler ultrasound on endotheliumdependent dilation of congestive heart failure treated with Kanli Decoction," Journal of Chinese Integrative Medicine, vol. 2, no. 4, pp. 268-270, 2004.

[12] Y. F. Li, F. F. Cao, F. Liu, X. Y. Bai, and Y. Lu, "Effects of Shexiangbaoxin pills on the expression of cardiac alpha (1)and beta-adrenergic receptor subtypes in rat hearts with heart failure induced by myocardial infarction," Chinese Medical Journal, vol. 125, pp. 1556-1562, 2012.

[13] J. Luo and H. Xu, "Outcome measures of chinese herbal medicine for coronary heart disease: an overview of systematic reviews," Evidence-Based Complementary and Alternative Medicine, vol. 2012, Article ID 927392, 9 pages, 2012.

[14] Z. Zhang, Shang Han Lun (Discussion of Cold-Induced Disorders), Public Health Press, 2005.

[15] W. Dietl, K. Trescher, P. Hohensinner et al., "SiNiTang-a traditional Chinese herbal remedy improves cardiac function post-MI," Journal of Clinical \& Experimental Cardiology, vol. 5, pp. 1-4, 2012.

[16] K. Peter K, J. Schinnerl, S. Felsinger et al., "A novel concept for detoxification: complexation between aconitine and liquiritin in a Chinese herbal formula ("Sini Tang")," Journal of Ethnopharmacology, vol. 149, pp. 562-569, 2013.

[17] J. H. Boyd, S. Mathur, Y. Wang, R. M. Bateman, and K. R. Walley, "Toll-like receptor stimulation in cardiomyoctes decreases contractility and initiates an NF- $\kappa \mathrm{B}$ dependent inflammatory response," Cardiovascular Research, vol. 72, no. 3, pp. 384-393, 2006.

[18] F. Arslan, M. B. Smeets, L. A. J. O’Neill et al., "Myocardial ischemia/reperfusion injury is mediated by leukocytic toll-like receptor- 2 and reduced by systemic administration of a novel anti-toll-like receptor-2 antibody," Circulation, vol. 121, no. 1, pp. 80-90, 2010.

[19] J. Favre, P. Musette, V. Douin-Echinard et al., "Toll-like receptors 2-deficient mice are protected against postischemic coronary endothelial dysfunction," Arteriosclerosis, Thrombosis, and Vascular Biology, vol. 27, no. 5, pp. 1064-1071, 2007.

[20] J.-I. Oyama, C. Blais Jr., X. Liu et al., "Reduced myocardial ischemia-reperfusion injury in toll-like receptor 4-deficient mice," Circulation, vol. 109, no. 6, pp. 784-789, 2004.
[21] S. Llorens, J. Jordán, and E. Nava, "The nitric oxide pathway in the cardiovascular system," Journal of Physiology and Biochemistry, vol. 58, no. 3, pp. 179-188, 2002.

[22] J. E. Toblli, F. DiGennaro, J. F. Giani, and F. P. Dominici, "Nebivolol: impact on cardiac and endothelial function and clinical utility," Vascular Health and Risk Management, vol. 8, pp. 151-160, 2012.

[23] B. Boyer, K. W. Hart, M. I. Sperling, C. J. Lindsell, and S. P. Collins, "Biomarker changes during acute heart failure treatment," Congestive Heart Failure, vol. 18, no. 2, pp. 91-97, 2012.

[24] J. R. Dietz, "Mechanisms of atrial natriuretic peptide secretion from the atrium," Cardiovascular Research, vol. 68, no. 1, pp. 8$17,2005$.

[25] V. Cannone, B. K. Huntley, T. M. Olson et al., "Atrial natriuretic peptide genetic variant rs5065 and risk for cardiovascular disease in the general community: a 9-year follow-up study," Hypertension, vol. 62, no. 5, pp. 860-865, 2013.

[26] H. K. Gaggin, L. James, and J. L. Januzzi Jr., "Biomarkers and diagnostics in heart failure," Biochimica et Biophysica Acta, vol. 1832, no. 12, pp. 2442-2450, 2013.

[27] T. M. Kolettis, M. Barton, D. Langleben, and Y. Matsumura, "Endothelin in coronary artery disease and myocardial infarction," Cardiology in Review, vol. 21, no. 5, pp. 249-256, 2013.

[28] C. Borghi, P. Marino, P. Zardini, B. Magnani, S. Collatina, and E. Ambrosioni, "Short- and long-term effects of early fosinopril administration in patients with acute anterior myocardial infarction undergoing intravenous thrombolysis: results from the Fosinopril in Acute Myocardial Infarction Study," American Heart Journal, vol. 136, no. 2, pp. 213-225, 1998.

[29] D. P. Bicket, "Using ACE inhibitors appropriately, American Family Physician, vol. 66, no. 3, pp. 461-473, 2002.

[30] A. E. Berezin, "Effect of fosinopril on the rate of neurohumoral and proinflammatory activation in patients with heart failure," Klinicheskaia Meditsina, vol. 82, no. 9, pp. 29-32, 2004.

[31] I. Resources, Guide for the Care and Use of Laboratory Animals, Commission on Life Sciences, National Research Council. National Academy Press, Washington, DC, USA, 1996.

[32] D. Csupor, E. M. Wenzig, I. Zupkó, K. Wölkart, J. Hohmann, and R. Bauer, "Qualitative and quantitative analysis of aconitine-type and lipo-alkaloids of Aconitum carmichaelii roots," Journal of Chromatography A, vol. 1216, no. 11, pp. 2079-2086, 2009.

[33] J. M. Pfeffer, M. A. Pfeffer, P. J. Fletcher, and E. Braunwald, "Ventricular performance in rats with myocardial infarction and failure," American Journal of Medicine, vol. 76, pp. 99-103, 1984.

[34] H.-J. Yin, Y. Zhang, and Y.-R. Jiang, "Effect of folium panax quinquefolium saponins on apoptosis of cardiac muscle cells and apoptosis-related gene expression in rats with acute myocardial infarction," Chinese Journal of Integrated Traditional and Western Medicine, vol. 25, no. 3, pp. 232-235, 2005.

[35] H.-J. Yin, Y. Zhang, and Y.-R. Jiang, "Effect of folium panax quinquefolium saponins on apoptosis of cardiac muscle cells and apoptosis-related gene expression in rats with acute myocardial infarction," Chinese Journal of Integrated Traditional and Western Medicine, vol. 25, no. 3, pp. 232-235, 2005.

[36] M. J. Koren, R. B. Devereux, P. N. Casale, D. D. Savage, and J. H. Laragh, "Relation of left ventricular mass and geometry to morbidity and mortality in uncomplicated essential hypertension," Annals of Internal Medicine, vol. 114, no. 5, pp. 345-352, 1991. 
[37] A.-M. Wu, M.-J. Zhao, and D.-M. Zhang, "Characteristics of TCM syndrome and appraisal with echocardiography in heart failure rats after myocardial infarction," Chinese Journal of Integrated Traditional and Western Medicine, vol. 27, no. 3, pp. 227-230, 2007.

[38] J. Takagawa, Y. Zhang, M. L. Wong et al., "Myocardial infarct size measurement in the mouse chronic infarction model: comparison of area- and length-based approaches," Journal of Applied Physiology, vol. 102, no. 6, pp. 2104-2111, 2007.

[39] M. Panteghini, "Role and importance of biochemical markers in clinical cardiology," European Heart Journal, vol. 25, no. 14, pp. 1187-1196, 2004.

[40] Y. Sato, H. Fujiwara, and Y. Takatsu, "Biochemical markers in heart failure," Journal of Cardiology, vol. 59, no. 1, pp. 1-7, 2012.

[41] V. C. Chung, M. Chen, Q. Ying et al., "Add-on effect of chinese herbal medicine on mortality in myocardial infarction: systematic review and meta-analysis of randomized controlled trials," Evidence-Based Complementary and Alternative Medicine, vol. 2013, Article ID 675906, 12 pages, 2013.

[42] A. Evangelista, F. Flachskampf, P. Lancellotti et al., "European Association of Echocardiography recommendations for standardization of performance, digital storage and reporting of echocardiographic studies," European Journal of Echocardiography, vol. 9, no. 4, pp. 438-448, 2008.

[43] X. Yang, Z. Chong, and Y. Guo, "The regulating effects of Sinitang on vasoactive substance in rats with renal hypertension," Chinese Journal of Clinical Pharmacy, vol. 28, 2008.

[44] S. R. Kapadia, H. Oral, J. Lee, M. Nakano, G. E. Taffet, and D. L. Mann, "Hemodynamic regulation of tumor necrosis factor$\alpha$ gene and protein expression in adult feline myocardium," Circulation Research, vol. 81, no. 2, pp. 187-195, 1997.

[45] Q. Fan, “Science of prescriptions," in A Newly Compiled Practical English-Chinese Library of Traditional Chinese Medicine, pp. 9496, Publishing House of Shanghai University of Traditional Chinese Medicine, 2002.

[46] R. C. Lantz, G. J. Chen, M. Sarihan, A. M. Sólyom, S. D. Jolad, and B. N. Timmermann, "The effect of extracts from ginger rhizome on inflammatory mediator production," Phytomedicine, vol. 14, no. 2-3, pp. 123-128, 2007.

[47] H. Ueda, K. Ippoushi, and A. Takeuchi, "Repeated oral administration of a squeezed ginger (Zingiber officinale) extract augmented the serum corticosterone level and had antiinflammatory properties," Bioscience, Biotechnology and Biochemistry, vol. 74, no. 11, pp. 2248-2252, 2010.

[48] J. S. Hwa, Y. C. Jin, Y. S. Lee et al., "2-methoxycinnamaldehyde from Cinnamomum cassia reduces rat myocardial ischemia and reperfusion injury in vivo due to HO-1 induction," Journal of Ethnopharmacology, vol. 139, no. 2, pp. 605-615, 2012.

[49] L. Siracusa, A. Saija, M. Cristani et al., "Phytocomplexes from liquorice (Glycyrrhiza glabra L.) leaves-chemical characterization and evaluation of their antioxidant, anti-genotoxic and anti-inflammatory activity," Fitoterapia, vol. 82, no. 4, pp. 546556, 2011.

[50] S.-W. Kim, Y. Jin, J.-H. Shin et al., "Glycyrrhizic acid affords robust neuroprotection in the postischemic brain via antiinflammatory effect by inhibiting HMGB1 phosphorylation and secretion," Neurobiology of Disease, vol. 46, no. 1, pp. 147-156, 2012. 


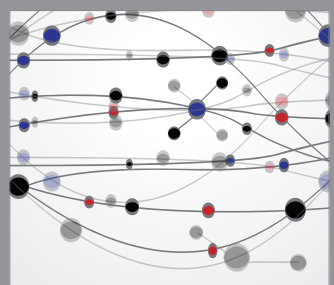

The Scientific World Journal
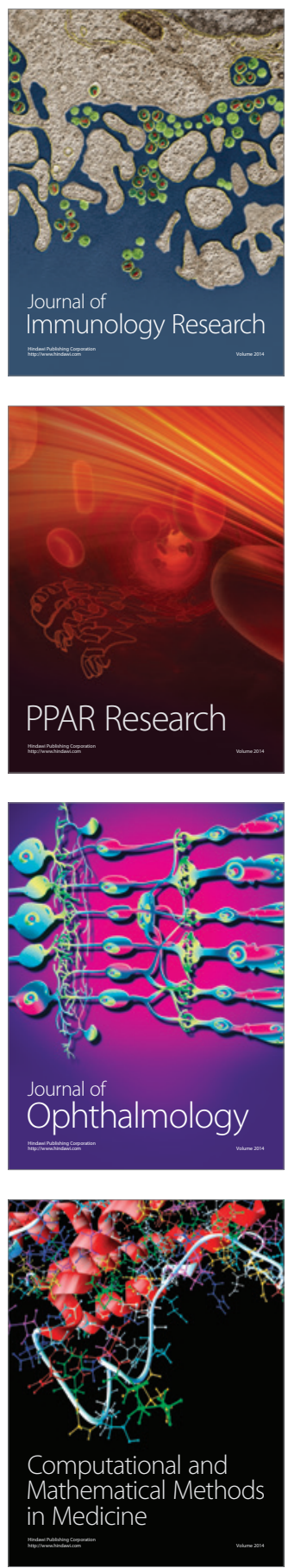

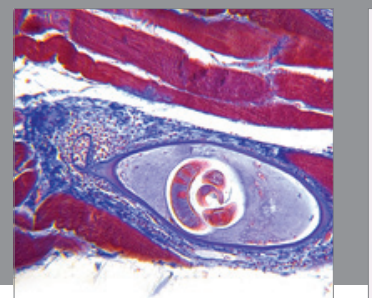

Gastroenterology

Research and Practice
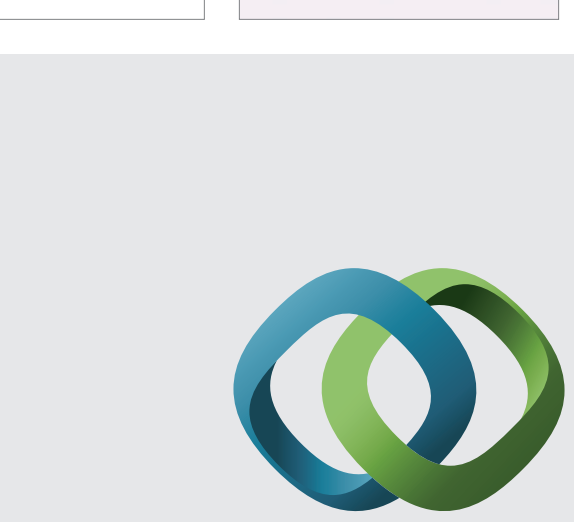

\section{Hindawi}

Submit your manuscripts at

http://www.hindawi.com
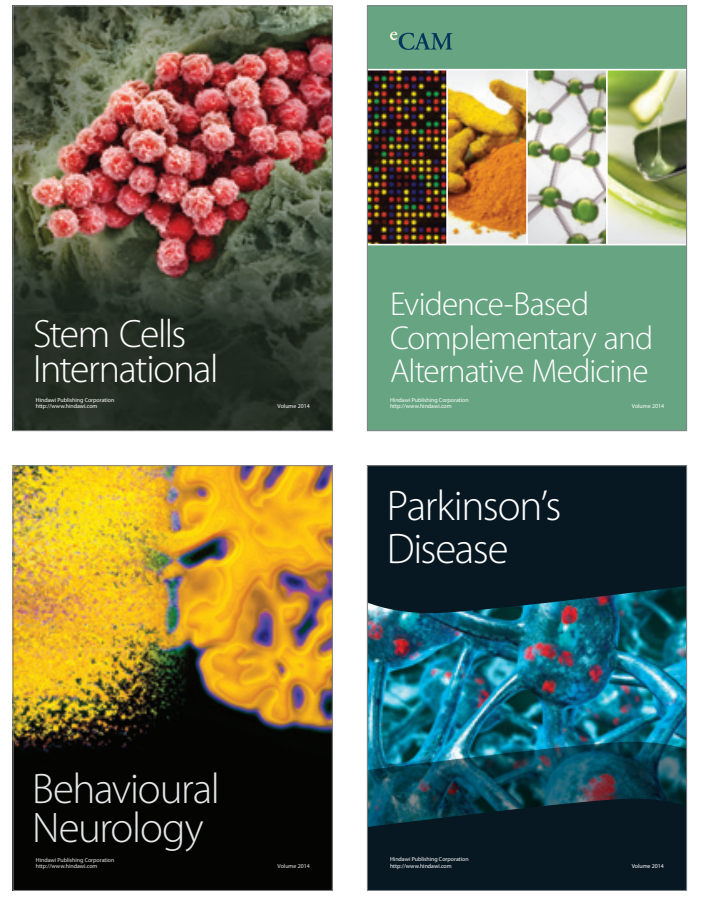
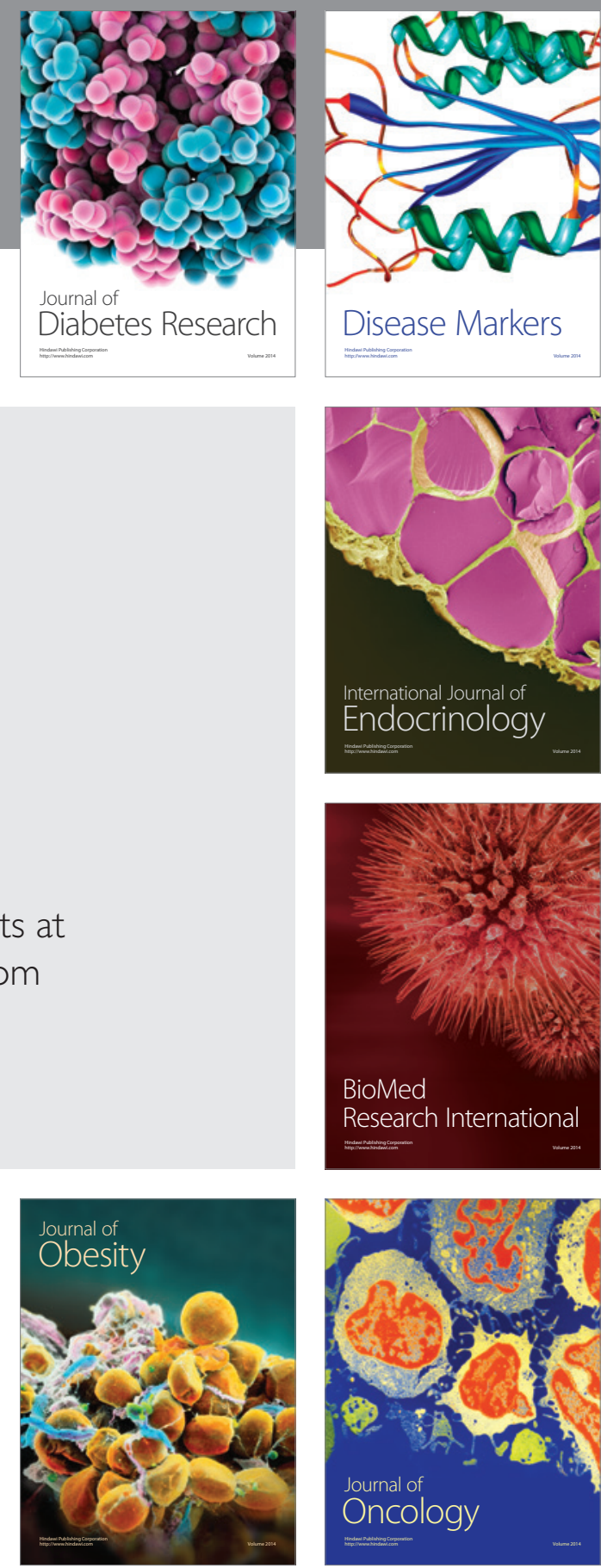

Disease Markers
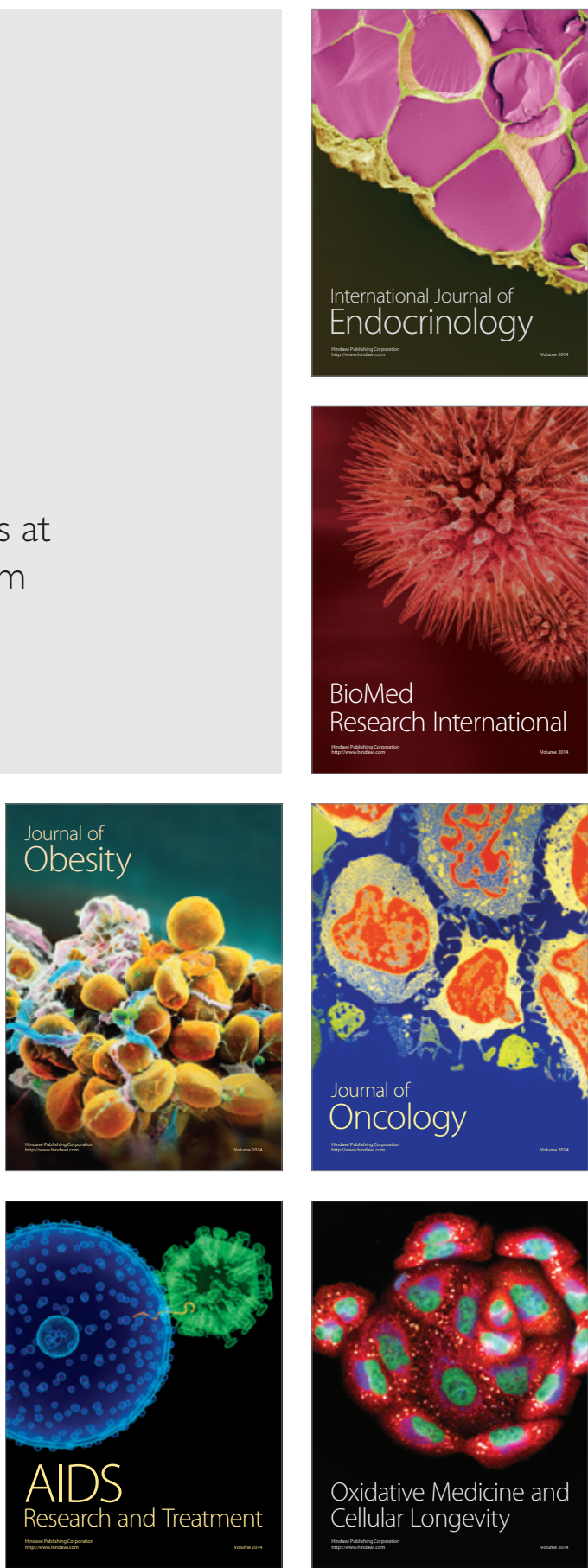